\section{THE PUY-DE-DÓME OBSERVATORY}

WE have already given some information concerning this important meteorological observatory, and today we present three illustrations showing its site and construction.

The site of this observatory is 1,465 metres above the level of the sea and about r,ooo metres above the level of Rabanesse, the meteorological station connected with it and situated in the gardens of the Clermont Faculty of Sciences. The Puy-de-Dôme was in ancient times supposed to have been the scene of so-called Druidical sacrifices, and was certainly the seat of a Roman temple, probably of Mercury. In excavating the mountain for the foundation of the observatory the extensive ruins of this temple were again brought to light. A number of medals, statues, and other objects have already been found and collected in a special museum. But it is intended to replace them in a repository which is to be bui.t on the very top of the mountain.

It was on September 19, 1648 , that Perrier, the then president of the Cour des Aides, verified on the top of the Puy-de-Dôme the great law of the diminution of pressure discovered by his brother-in-law, Pascal. Descartes says somewhere that he had suggested the experiment to Pascal. The illustrious philosopher was then an exile at Stockholm, where he died a few years afterwards. He was keeping up correspondence through Father Mersenne with a number of French savants, and especially with Perrier, Comparative observations for obtaining the height of the mercury were carried on during the years I649, I650, and I65I at Clermont, at the Couvent des Minimes at Storkholm in the palace of the queen by Descartes, and after his demise by one of his friends, and at Paris by an observer whose name has not been preserved.

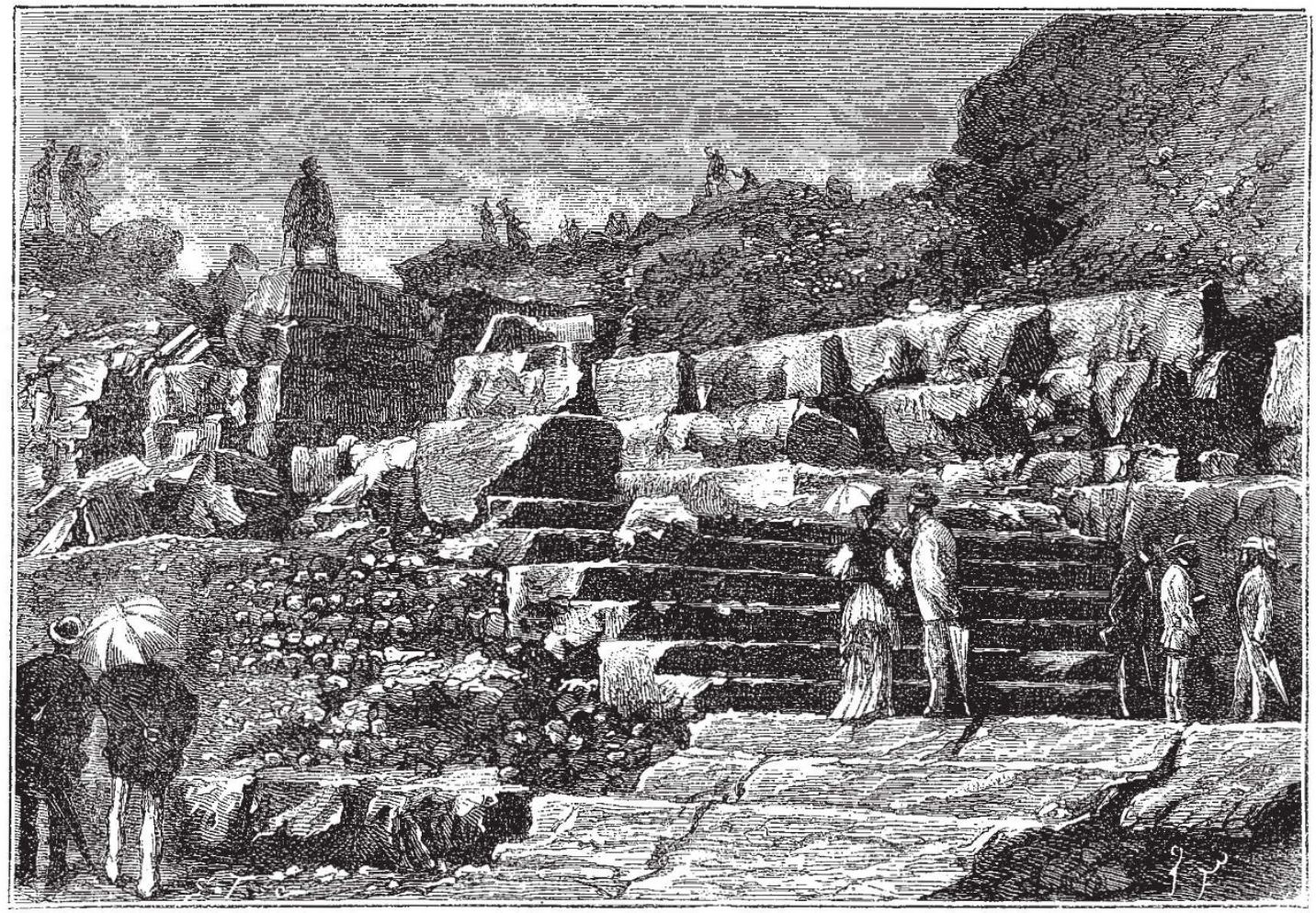

Fig. 1.-View of the Ruins of the Roman Temple beside the Puy-de-Dôme Observatory.

The idea of building an observatory on the Puy-de Dôme was originated by M. Alluard, the present director, about fifteen years ago. It was supported first by M. Duruy, the Minister of Public Instruction, under the Empire. M. Faye, then on a tour in the capacity of general inspector, approved it, and reported favourably. The astronomer paid more than one visit to the Puyde-Dôme to ascertain the practicability of the proposal, which was supported also by $M$. Leverrier.

Up to the present moment the Government have paid only the expenses for the instruments, the whole of the costs of building having been supported by the Department and city of Clermont. The expenses have amounted to $10,000 l$.

The distance from Clermont to the Puy-de-Dôme is about ten kilometres, six of which can be done in a cart. A mountain road has been made at the expense of the Department, and with very little difficulty; the track of the old via Romana had only to be followed.j
Commandant Perrier, Director of the French Ordnance Survey, has established a barracks close to the observatory for determining, by electricity, the latitude of the Puy-de-Dôme. He will continue his work as long as the state of weather permits. For such observations the Puyde-Dôme is connected telegraphically with Mount Souris.

The observatory, as we have already intimated, was inaugurated on August 22, during the meeting of the French Association at Clermont. Eight hundred persons made a pilgrimage to the top of the Puy-de-Dôme, to be present at the opening, and in spite of the unfavourable state of the weather, the ceremony was successful. Under an enormous tent a collation was provided for the visitors, and after the repast, many pleasant congratulatory speeches were made. M. Bardoux, president of the General Council, in speaking eloquently of Pascal, whose name is intimately associated with the Puy-de-Dôme, announced that the Government intended to erect a bronze statue to the great philosopher, in Clermont. Dr. 
Janssen spoke in the name of the Meteorological Society of France, described the celebrated experiment which Pascal made on the mountain and the barometer which he used, and showed what science owes to the observations made with this precious instrument. He at the same time announced that the Meteorological Society had awarded to $M$. Alluard a first silver medal. Many other eloquent speeches were made, in all of which reverential reference was made to the immortal Pascal.

The observatory consists of two distinct parts-the house of the keeper and the meteorological building. The former comprises, first, the telegraph office, from which messages are sent to the station on the plain, and alongside of which are apartments for the keeper, who has

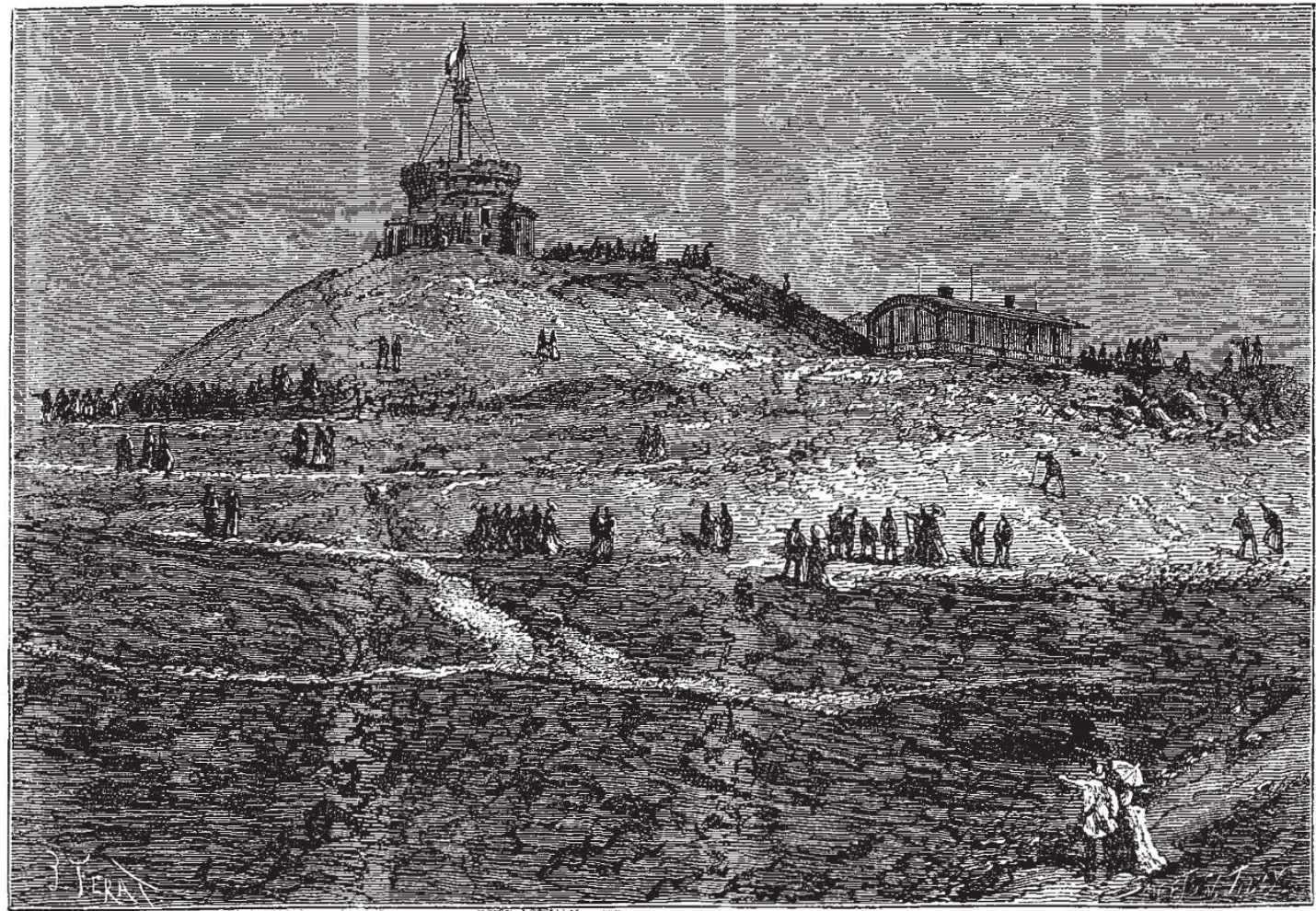

Fig. 2.-Puy-de-Dôme Observatory on the Day of its Inauguration, August 22, 1876.

been chosen by M. Alluard from the navy. On the first floor are apartments for the director, and several rooms reserved for savants who may wish to sojourn on the

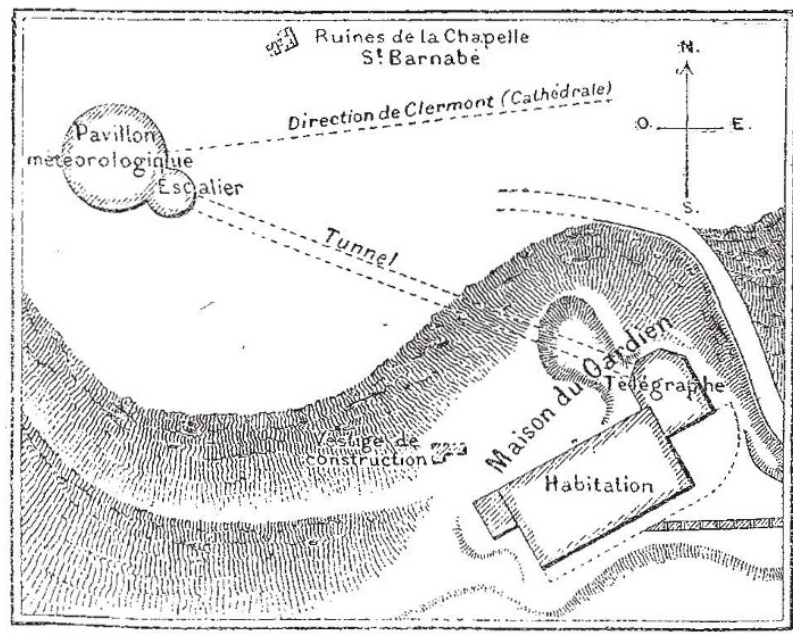

Fif, 3.-Plan of the Puy-de-Dôme Observatory.

summit of the peak to carry on observations. The body of this building communicates with the meteorological building by a subterranean tunnel. The latter building comprises an underground floor built above a vault, and another upper story which is on a level with the summit of the peak.

Traversing the tunnel from the house of the keeper, we reach the lower part of the meteorological building: this is a valult into which the light of day does not penetrate. It is intended for the magnetic chamber, and will be kept dry by a thorough ventilation, the walls being covered with cement. The first floor above this, is also underground, but is provided with two holes, by which the light enters. It constitutes a circular chamber, surrounded by a corridor, for the purpose of enveloping it in a layer of insulating air. Here will be placed the apparatus, the regular working of which requires a constant temperature, and among which we may mention Redier's registering barometer. The upper story, as we have said, is level with the ground, and forms a beautiful building, provided with four windows, adjusted to the four points of the compass. It communicates with a sinall external louvered cage, containing the various classes of thermometers. Inside are the following instruments :- (I) M. Hervé Mangon's anemograph, communicating by electric wires with the Robinson anemometer, placed on the top of the fixed mast on the upper part of the tower ; (2) Mangon's register or pluviometer ; (3) M. Hasler's thermohygrograph ; (4) Fortin's and TonneletRenou's barometers ; (5) regulating clock ; (6) astronomical telescope. This portion of the building is furnished with tables placed between each window.

Independently of the observations recorded by the registering apparatus, the keeper makes observations 
every three hours, transmitting them by telegraph to the station on the plain. These observations on the summit and those on the plain are compared conjointly with the message which arrives at midday from the Paris Observatory. On these are based the meteorological bulletin of the department.

The station on the plain at Rabanesse is installed in a house provided with a quadrangular tower of 15 metres in height. It is provided with a large shelter for the thermometers, and M. Alluard has had a fine photographic studio constructed, in which he intends to organise a regular service for photographing clouds. Other ingenious and beautiful arrangements have been made here, and the entire establishment, on mountain and plain, is one of the most complete in existence, and may be expected to furnish much valuable meteorological data.

For the illustrations we are indebted to our French contemporary, La Nature.

\section{ON THE APPARATUS EMPLOYED BY THE \\ LATE MR. GRAHAM, F.R.S., IN HIS RESEARCHES ${ }^{1}$}

MR. GRAHAM will probably be best remembered as a chemist, although the most important of his researches where either purely physical, or were devoted to the elucidation of questions which occupy an intermediate position between physics and chemistry. It is specially interesting, therefore, to observe what was the nature of the apparatus he employed in

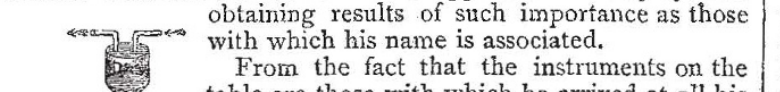
From the fact that the instruments on the table are those with which he arrived at all his more important conclusions, it will at once be evident that the appliances he used were both few and simple. Before I proceed to describe them, I should, as the time at my disposal is very limited, briefly state that Graham's labours were mainly devoted to ascertaining the nature of molecular movement in cases in which he was satisfied that no mass movement could take place, and, as Dr. Angus Smith has pointed out, while Dalton showed the relative weights of the combining quantities, Graham showed the relative magnitude of groups into which they resolve themselves. It is interesting to note that, as Prof. J. P. Cooke has obseryed, while Faraday was so successfully developing the principles of electrical action, Graham, with equal success, was investigating the laws of molecular motion. Each followed with wonderful constancy, as well as skill, a single line of study from first to last, and to this concentration of power their great discoveries are largely due.

Fig. 2. The Royal Society's Catalogue of papers shows that his earliest paper was on the absorption of gases by liquids. It was published in 1826 in Thor son's "Annals of Philosophy"; in it he considers that gases owe their absorption in liquids to their capability of being liquefied, and therefore that solutions of gases in liquids are mixtures of a more volatile with a less volatile liquid. He concludes the paper by saying, that "All that is insisted on in the foregoing sketch is, that when gases appear to be absorbed by liquids they are simply reduced to that liquid inelastic form which otherwise, by cold or pressure, they might be made to assume, and their detention in the absorbing liquid is owing to that mutual affinity between liquids which is so common." It was a theoretical paper only, and no apparatus was even described ; I have quoted it merely because, in his last paper in the Phil. Trans., more than thirty years afterwards, he speaks of the liquefaction of gas in colloids in much the same terms.

In 1829 , the Quarterly Fournal of Science ${ }^{2}$ contains his first paper on the diffusion of gases; he found that the lighter a gas

r Lecture by W. Chandler Roberts, F.R S., Chemist of the Mint, at the Loan Collection, South Kensington.

a Quart. Journ. Sci., ii., $\$ 829$, p. 74 is the more quickly it diffuses away from an open cylinder. The cylinders he employed were nine inches long, and 0.9 inches interior diameter; they were placed in a horizontal position, and the gas under examination was allowed to diffuse outwards through a narrow tube directed either upwards or downwards according as the gas was heavier or lighter than air. It was therefore

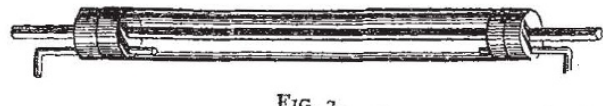

by the aid of a simple cylinder that he was led to believe, as he states in this his first paper, "that the diffusiveness of gases is inversely as some function of their density, apparently the square root of their density." $\mathrm{He}$ subsequently found that so great is the tendency of gases to diffuse into one another, that this mixture or inter-diffusion will take place through apertures of insen-

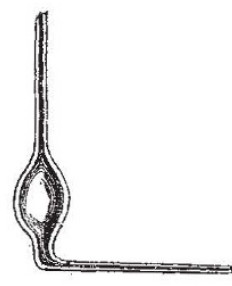

FIG. 4.

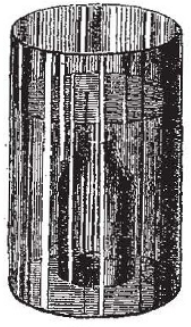

Frg. 5. sible magnitude. And in bis paper in $1834,{ }^{1}$ he treats in detail of diffusion through porous septa, his object being " to establish with numerical exactness the following law of diffusion of gases:-The diffusion or spontaneous intermixture of two gases in contact is effected by an interchange in position of indefinitely minute volumes of the gases, which volumes are not

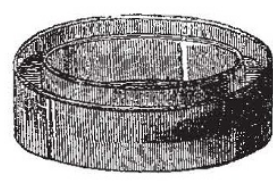

Fig. 6.

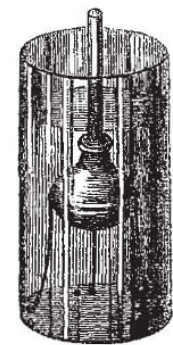

FtG. \%.

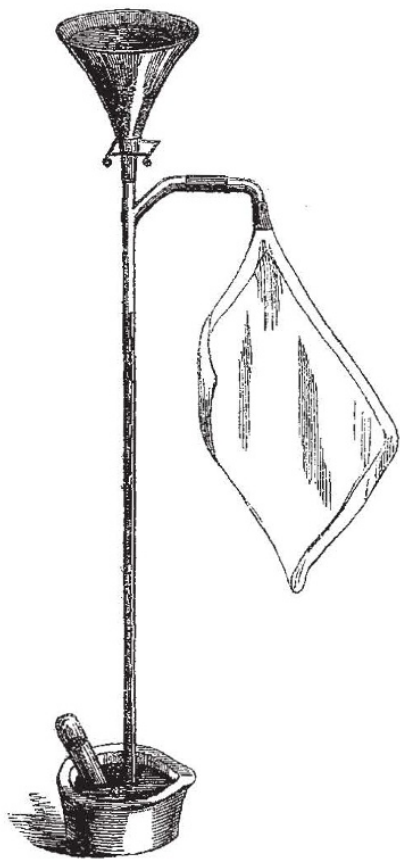

Fig 8 . necessarily of equal magnitude, being, in the case of each gas, inversely proportional to the square-root of the density of that gas." He started from the well-known experiment of Döbereiner, who found, in 1825, that hydrogen kept in; a glass receiver standing over water, escaped by degrees through the fissure into the surrounding air, the water in the receiver rising I Edin, Roy. Soc. Trans., xii., 1834, p. 222. 